\title{
A good time to raise standards
}

EVERY year we scan the statistics of The Universities Central Council on Admission (UCCA) for trends, and occasionally we get rapped over the knuckles for misinterpretation. This year's figures, just out, offer the usual happy hunting ground.

The statistics, as always a year late, refer to those who applied during the year 1975-76, generally for entry in October 1976. They show applications up again to around 142,000 . Overseas candidates, particularly from the Commonwealth, continue to grow in number more rapidly than home candidates-in 1976 they accounted for one in seven of all applicants. Places were found for 74,000 applicants; the figure for total applicants, which is always about twice the number accepted, includes a large number who subsequently fail to gain adequate school qualifications, who withdraw, who are applying for the second time and so on. So it must not be inferred that there is a genuine shortage of places.

Engineering continues its run of popularity (which started well before the recent governmental campaign). Projections to 1977 suggest there are now at least $40 \%$ more applying for engineering than in 1972. And even mathematics, physics and chemistry-which lost popularity until 1975-may now be sharing again in the general rise in applications.
Simple head-counting, however, conceals some striking variations in quality. The relative paucity of candidates in mathematics, physics and chemistry does not seem to have led to a diminished standard in those accepted-at least as far as paper qualifications go. Indeed the school performances of accepted physicists rival those of accepted medical students - the latter a category in which unjersities can be very selective. Good scientists still seem to be coming forward. The position is somewhat different in engineering. Rising quality has not gone along with rising numbers, which may mean that schools have been urging more of their modestly accomplished pupils to consider engineering.

It is against this background that one must consider the suggestion made in the report that universities may soon have to allocate further resources to alleviate the 'critical situation' which seems to be developing in engineering places. Only two or three years ago, of course, we were being told by the engineers of half-empty departments: it is hard to believe the turn-around has been that dramatic. But maybe the universities. rather than create more spaces, should become more selective as time goes on, in the hope of creating a genuine impression amongst students not just that the country welcomes engineers, but that standards in engineering are high.

\section{Research funding: the new trichotomy}

William S. Hillman comments on the relevance of the dichotomy of 'pure' and 'applied' science

THE dichotomy contrasting 'basic' and 'applied' research is still commonplace in discussions on funding. Such discussions of ten conclude that one mode is over-supported at the expense of the other. Yet on most reasonable definitions of the two, history suggests that neither prospers alone. The old dichotomy is at best misleading, and distracts attention from a more immediately dangerous aspect of current policies. That aspect invites analysis by trichotomy, if you will excuse such language.

Strictly speaking, nothing in the current situation is entirely new. Reasonably enough, the patrons of science have always wanted useful results, quickly if possible. But the main dispenser of patronage now is government, with its self-justifying administrative hierarchies, and it has finally become clear that the taxpayers' resources are finite. In addition, occasional spectacular successes, such as moon landings, have been inappropriately but invidiously contrasted with (for example) the 'failure' of NIH research to abolish cancer. Recent versions of the king's desire for the alchemists' gold have thus split research into at least three recognisable types: real, imitation (or administrative) and defensive. The terms are not quite self-explanatory, but they correspond roughly to real gold, fool's gold and the elusive quicksilver.

Real research is originated, organised and carried out by investigators who understand the field in question. It is aimed at problems which in the view of those investigators are both important and reasonably likely to reward the effort with some return in understanding, control or both. The 'applied/basic' dichotomy is meaningless here. A salient characteristic of real research is that it engages the best judgment of capable scientists. The subjective elements in this description (who is 'capable'?) do not obscure the distinction between it and the second category.
Imitation research, in contrast. starts with the belief that, because science has proved useful in the past, scientists should be able to do anything, right now, given the funds, proper organisation and (most important) what sports writers call desire. This is all regardless of whether the necessary concepts, techniques and people actually exist. The primary motive for organising imitation research is neither controlling nor understanding nature, but pleasing one's superiors. That those superiors should know little about the opportunities and limitations in specialised fields is inevitable, but many organisers of imitation research either share that ignorance or are simply cynical. Hence manifold reports, detailed timetables and complex flow charts are prominent features of the game, leading naturally to the synonym 'administrative research'. The overriding rule is that the players must avoid being corrupted by luxuries such as intellectual rigour, imagination and patience; to that end, frequent exercises in relevance, interdisciplinary communications modalities and urgency are scheduled.

What, finally, is defensive research? The notion is analogous to that of defensive driving in that both recognise the hazards of assuming people will hehave sensibly; or to the developing style of defensive medicine, in which procedures that are legal safeguards for the physician may be wasteful for both the patient and society. Defensive research, in short, is what so many scientists must do who would prefer to be doing real research but lack private incomes. The result is that a core of real research becomes surrounded with a set of possibly quite worthless elements designed to impress those who want the gaudy imitation rather than await the real thing.

There is no space here for examples, but few readers will need them. Very likely some policy-makers, here and there, in one agency or another, will indignantly deny any knowledge of imitation or defensive research. But they are easily answered with a paraphrase of the ancient epitaph: if you need examples, look around you. 